\title{
SPECIAL PURPOSE DRILLING MACHINE FOR SHIP HULLS
}

\author{
Ajit Salunke', Swapnil Ramani², Mahesh Caisucar ${ }^{3}$ \\ ${ }^{1}$ Assistant Professor \& Head, Department of Mechanical Engineering, Don Bosco College of Engineering, Goa \\ ${ }^{2}$ Assistant Professor, Don Bosco College of Engineering, Fatorda, Goa \\ ${ }^{3}$ Assistant Professor, Goa Engineering College, Farmagudi, Goa
}

\begin{abstract}
The integrity of the ship depends on accurate assembly of the scuttle to the hull body. The workers face a great amount of difficulty in drilling the holes for mounting the scuttle on the hull body of the ship mostly due the lengthy and complicated procedure involved. This work provides a simplified procedure for drilling the holes and at the same time maintaining the accuracy of drilling. A special purpose drilling machine was designed, analyzed and fabricated to solve this issue.
\end{abstract}

Keywords: Drilling, Hull, Guide way, Slide way, Horizontal Bridge, Drilling Column.

\section{INTRODUCTION}

The workers at shipyards face a great amount of difficulty in drilling the holes for mounting the scuttle on the hull body of the ship. The integrity of the ship and the safety of the crew depends to a great extent on accurate assembly of the scuttle to the hull body. A Scuttle is a circular window fitted on the hull of the ship to admit light and air. It is a marine term for a window on a boat. and is known by different names in various parts of the world. They are called as a Sidelight in the Royal Navy and Porthole in merchant service. On a ship, the function of a scuttle is to provide light and fresh air to enter the dark and often damp below-deck quarters of the vessel. It also offers the below-deck occupants a limited but a much needed view of the outside world. A scuttle consists of at least two structural components and is, in its simplest form, similar to any other type of window in design and purpose. It is primarily a circular glass disk encased in a metal frame that is bolted securely into the side of a ship's hull. Scuttles range in diameter from several inches to more than two feet, and weigh from several pounds to over one hundred pounds. Much of the weight comes from its glass, which, on ships, can be as much as two inches thick. The Hull is the main body of the ship below the main outside deck. The hull consists of an outside covering (or skin) and an inside framework to which the skin is secured. The skin and framework are usually made of steel and secured by welding. Although the scuttle is a very small component the fitting of this small component follows a lengthy and complicated procedure. This project mainly aims at providing a simplified procedure for drilling the holes and at the same time maintaining the accuracy of drilling.

\section{LITERATURE REVIEW}

Sharad Kumar Shukla et. al analysed the vibration on radial drilling machine using piezoelectric sensor .The sensor measured the vibration of the machine and produced output in the form of voltage or current proportional to the vibration
[1]. Akshay R Mahendraker automated the Drilling Process Using Electro Pneumatics Systems and reported improved accuracy and repeatability of hole drilling compared to the conventional [2]. Prof. P.R. Sawant et al designed And developed a Special purpose Multi Drilling And Tapping Machine which led to Increase in productivity both qualitative and quantitative, Less human intervention, indirectly reduction in operator fatigue, Less rejection due to automatic controls, and increased the profit of company [3]. Kaushar H. Barad al automated Of Conventional Radial Drilling Machine. They observed that by use of this automation manufacturer can drill holes easily, more accurately and in less time, with minimum errors so manufacturing cost will also reduce [4].

\section{OVERVIEW}

The prototype special purpose drilling machine is divided into 4 components. They are

1) The Guide way 2) The Slide way 3) A Horizontal Bridge 4) A Drilling Column

Fig 1, gives a brief summary of the components required in the assembly of the actual prototype. The first component is called a guide way. This is the base component of the assembly. The whole prototype will be constructed upon it. The immediate next part which will be assembled on top of the guide way is the slide way. The slide way has to perform a dual function of first, supporting the horizontal bridge and the drilling column assembly upon itself. Secondly, it has to provide rotary motion to the whole machine. The horizontal bridge will hold the drilling column upon it. This bridge will help to set the radial distance at which the drilling is to be carried out. This way the machine can be designed to drill the holes of a variety of scuttle ranging in different sizes on a single machine. The last part in the assembly is the drilling column. The main function of the drilling column will be to hold the drilling machine on it and secondly, to provide the necessary vertical feed motion to the drilling machine. 


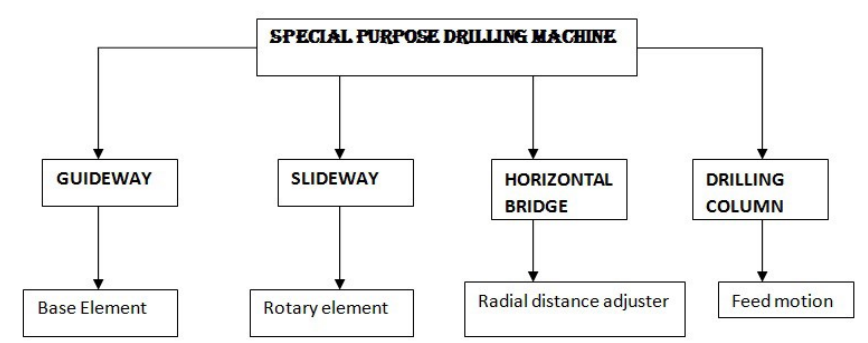

Fig.1 Block Diagram of Special Purpose Drilling Machine

\section{DESIGN AND ANALYSIS OF MECHANICAL}

\section{STRUCTURE}

\subsection{Guide Way}

The primary functions of a Guide way are to support other components of the machine on itself, provide a rigid and strong base ensuring the stability of the machine, dampen the vibrations arising from the drilling action of the drill bit on work piece and to hold the workpiece firmly. Guide way has a circular ring like structure. The circular geometry is selected keeping in mind that the holes to be drilled are along a circumference.

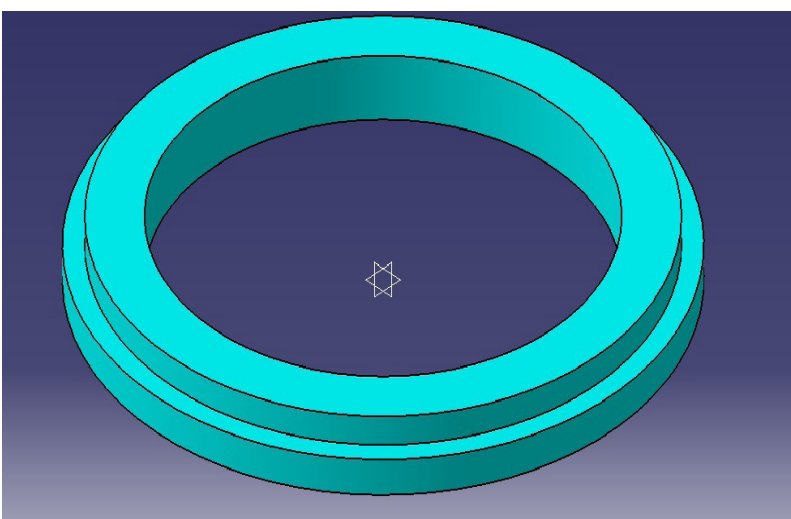

Fig 2.1 : Guide way design

The material chosen for the Guide way was cast iron. The cast iron has high compressive strength. It can take up huge load in the axial direction to which the guide way is usually subjected.

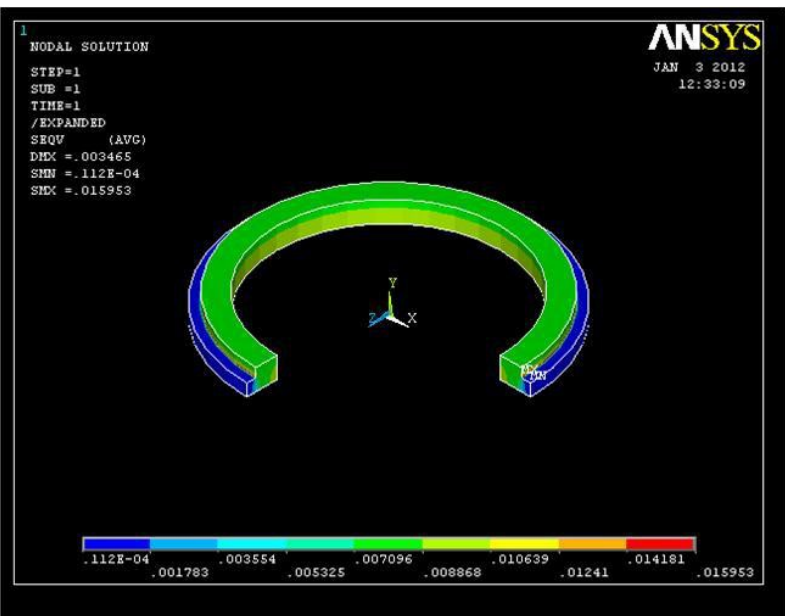

Fig 2.2: Stress Distribution of Guide way Using Ansys
Fig 2.2 shows the Von Mises stress distribution throughout the volume of the component. From the figure it can be seen that there is no severe variation in the stress distribution throughout the volume of the component. The value of stress varies from the highly safe region (theblue region) to the moderately safe region (the green region). Lower the variation of the Von Mises stress distribution, lower is the failure rate of the component.

\subsection{Slide Way}

The slide way is a complimentary ring like structure which sits on top of the guide way. Guide way and slide way are placed on top of each other in such a way that the male step of the guide way fits loosely into the female cavity of the slide way. Both the components share a common axis. While the guide way is a stationary component the slide way, will rotate about the axis providing the necessary indexing motion to the components which will be placed on it.

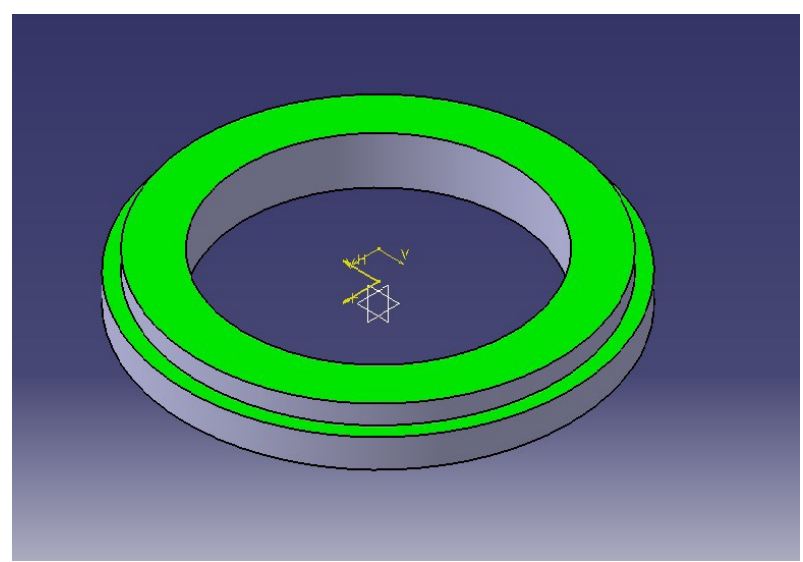

Fig 3: Slide way design

The motion between the slide way and the guide way must be smooth and frictionless so as to obtain more indexing motion with less effort. This can be effectively achieved my placing a bearing between the mating surfaces. The rolling thrust bearings were the choice of bearings to achieve this. Like the guide way, the material chosen for the slide way is cast iron.

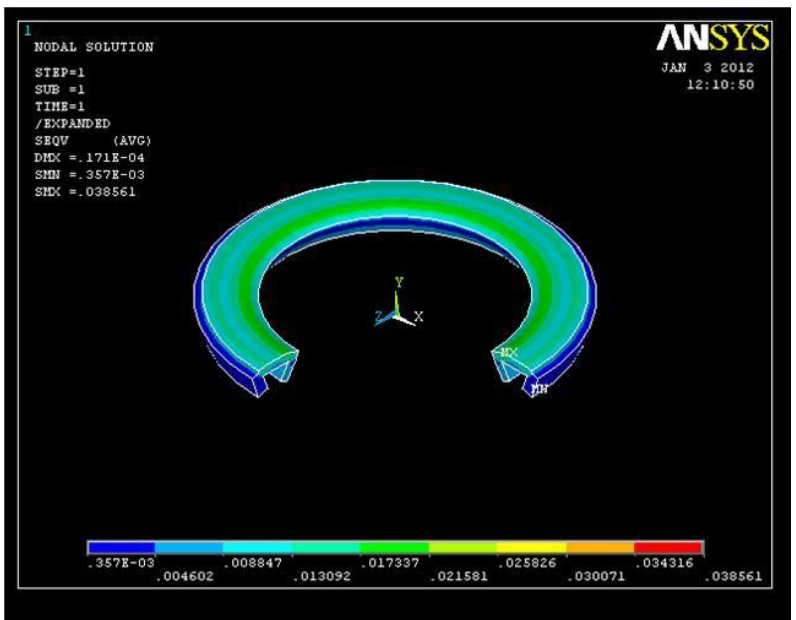

Fig 3.1 : Stress Distribution of Slide way Using Ansys 
In Fig 3.1 the Von Mises stress distribution throughout the volume of the component is shown. Just like the guide way analysis, the slide way too shows no major variation in the Von Mises stress distribution. The major portion of the volume is in the green zone which is still considered to be safe.

\subsection{Horizontal Bridge}

The bridge component is a system of three rod supported in an end support which supports a square bed upon it.

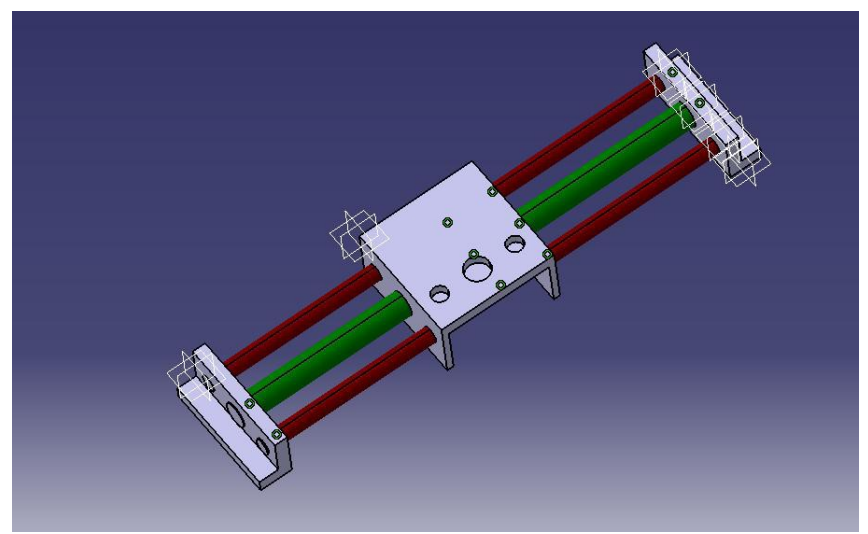

Fig. 4 Design of Horizontal Bridge

The end supports are bolted on the slide way. The middle rod is the thickest and is threaded to form a lead screw. This power screw is supported in bearings at both the

end supports. The bearings are fixed to the end supports by press fitting them into a bushing and then directly welding it to the end supports. The other two rods also known as support rods or tie rods are placed on either side of the power screw to support the bed. These rods are directly welded to the end supports. The power screw is free to rotate inside the bearing.

\section{FABRICATION}

From the fig. 2.1 it is evident that the dimension of the guide way corresponds to the dimension of the scuttle holes to be drilled. To fabricate a ring of such huge diameter is not possible via the usual method of turning on a lathe. Hence the above component was fabricated via the sand casting process.

The fabrication of the slideway is similar to the guideway fabrication. The component also was casted due its relatively large dimensions and then machined over the lathe to obtain the desired dimensions. Grooves were cut on the lower part of the circular cavity so that it forms a circular race or pathway for the steel balls to move around. For the horizontal bridge mechanism the mild steel rods were cut according to their lengths and threads were formed on the power screw shaft. A $10 \mathrm{~mm}$ thick plate was cut according to the above given dimensions and filed at the sides. Blind holes were drilled on top surface of the plate. Then the nuts were welded to opposite sides of this bed (on the bottom side).
The construction of the drilling column is similar to the horizontal bridge. The only difference being that the column is shorter in length. The power screw and the tie rod arrangement is exactly same as that used for the horizontal bed with the only exception being that this system of three rods is now arranged vertically. For stability purpose, the drilling column is supported on either side by mild steel plates. These plates performed the dual function of holding the three rod assembly parallel to each other and simultaneously prevent them from toppling over

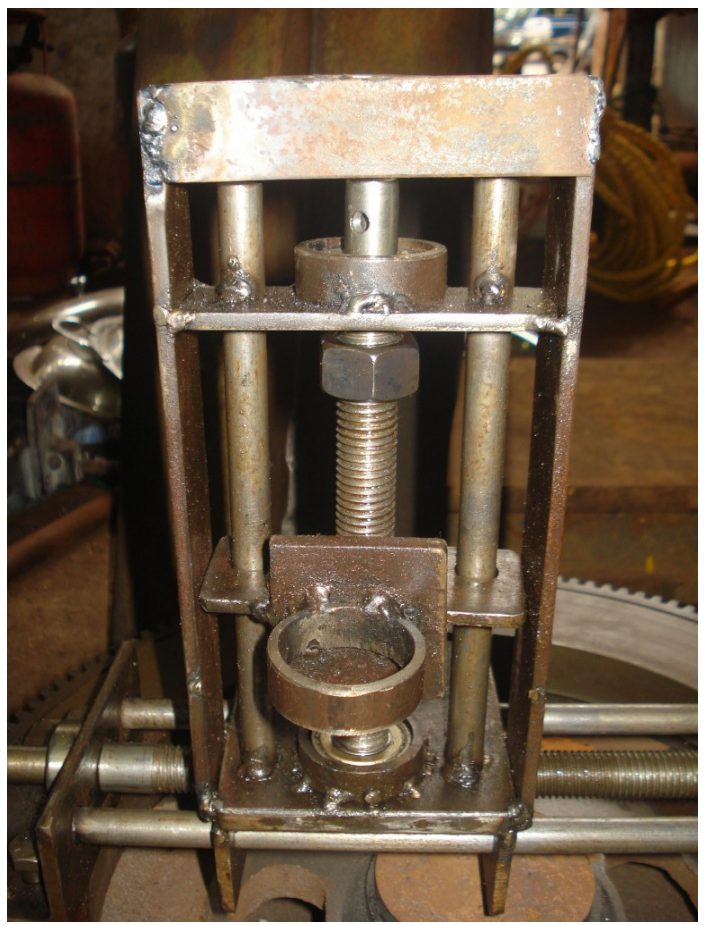

Fig 6. Drilling column

\section{FINAL ASSEMBLY}

The assembly of the drilling machine is quiet simple and it involves the following steps:

(i) First the Guide-way is mounted on top of the plate to be drilled. It is mounted with a suitable fixture. The base being heavy provides a rigid support for all the components mounted above it.

(ii)The balls are well placed in the groove of the guide way. The balls are not over packed together and not sparsely spaced.

(iii) In the third step the slide-way is placed on top of the guide-way.

(iv) The bridge is bolted on to the slide way by means of four bolts. The threads were formed using tapping in order to bolt the bridge.

(v) Motor is mounted at the top of the drilling column, which drives the horizontal power-screw. The rotation of the power-screw lowers and raises the plate to which the drilling motor is attached. 


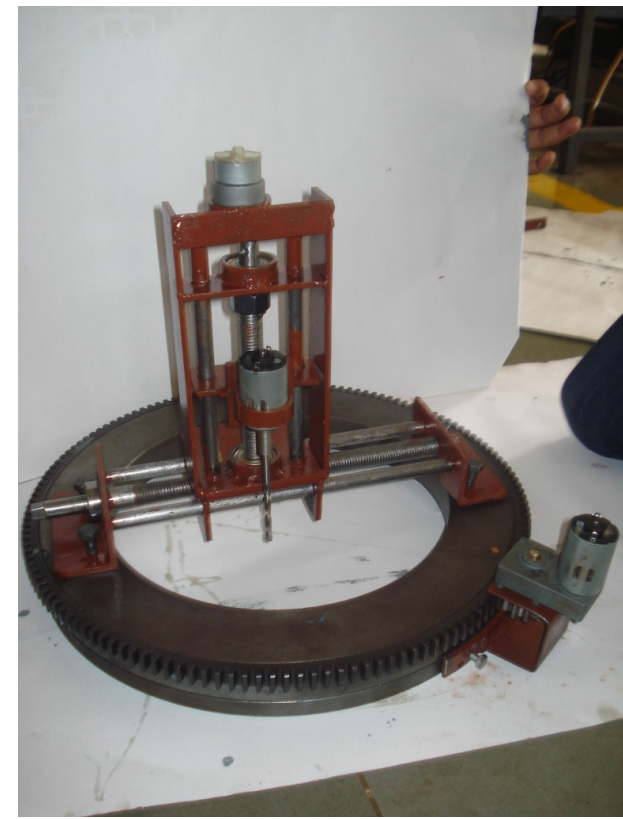

Fig 7 The complete assembly

\section{OVERVIEW OF AUTOMATION SYSTEM}

The drilling of the scuttle holes is a lengthy procedure, involving repetetive adjustment of the magnetic drilling machine to drill the holes at the required location. Since manual labour is required to operate the machine there is a tendency that errors might crop up during the actual machining due to negligence of the operator. Hence the need for automating the drilling mechanism.

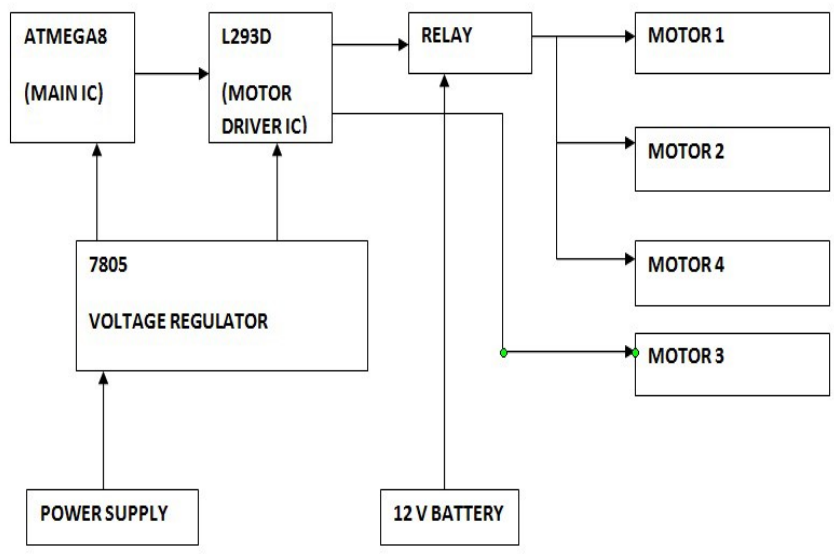

Fig 8. Block diagram of the Automation System

As can be seen from the block diagram, the main IC will be powered through a voltage regulator. The main IC is like the brain of the circuit. It stores instructions in on it and executed them in the sequence in which they are fed into it. The main IC is responsible for the logic of the circuit, if the circuit misfires it may be due to a faulty programme which may be burned inside the IC. The Main IC will then send the output to a motor driver IC. A motor driver IC is required to safeguard the main IC from the voltage fluctuations arising in the circuit. The motor driver IC is also powered by the same voltage regulator which supplies the voltage to the main IC. The voltage regulator is an important component of the circuit. Its working is on the similiar lines of an SMPS unit in a personal computer. The primary objective of the voltage regulator is to supply appropriate voltage to the main Ic. The main IC operates on a small voltage of about $5 \mathrm{~V}$ whereas the motor driver ic's operating range can be from 5 to $12 \mathrm{~V}$. This project uses a system of four motors. The motor 1 and motor 2 are interfaced with the starter ring of the assembly to obtain the necessary rotary indexing motion. The motor 3 is used to drive the vertical feed power screw to casue the up and down motion of the vertical bed. The last motor, i.e. motor 4 resembles the working of a drilling machine. This motor will run during the descent of the vertical bed and stop during the ascent of the same. Relays function as a switching devices into the circuit.

\section{AUTOMATION SYSTEM COMPONENTS}

\subsection{Main IC}

The main IC used in this project is ATMEGA8 IC. The Atmel AVR ATmega8 is a low-power CMOS 8-bit microcontroller based on the AVR RIS architecture. By executing powerful instructions in a single clock cycle, the ATmega8 outputs approaching $1 \mathrm{MIPS}$ per $\mathrm{MHz}$, allowing the system designer to optimize power consumption versus processing speed.

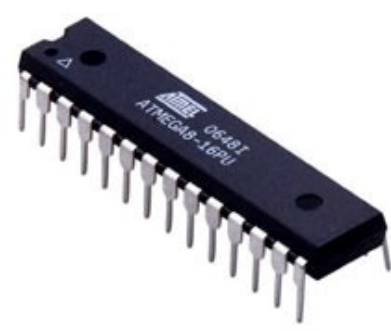

Fig 9 ATMEGA8 IC

\subsection{Driver IC}

The L293D is quadruple high-current half-H drivers. The L293D is designed to provide bi-directional drive currents of up to $1 \mathrm{~A}$ at voltages from $4.5 \mathrm{~V}$ to $36 \mathrm{~V}$. The $\mathrm{L} 293 \mathrm{D}$ is designed to provide bidirectional drive currents of up to 600$\mathrm{mA}$ at voltages from $4.5 \mathrm{~V}$ to $36 \mathrm{~V}$.

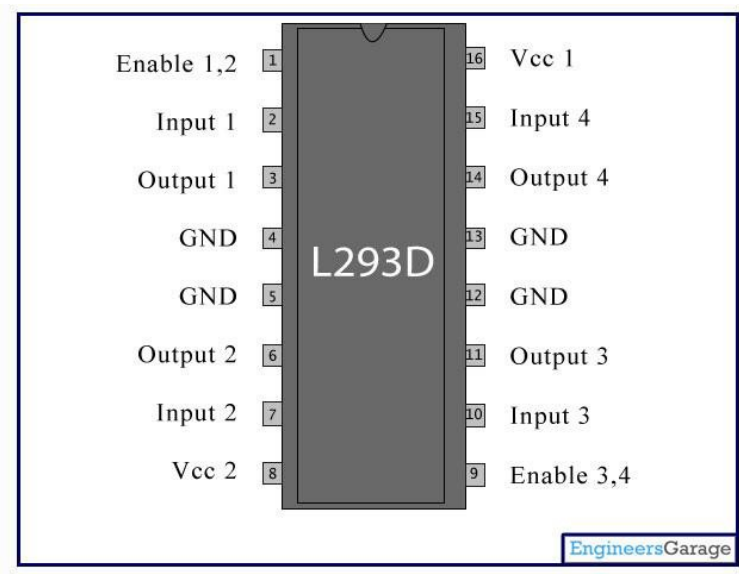

Fig 10 L293D Motor driver IC 


\subsection{Voltage Regulator}

The 78xx (sometimes LM78xx ) is a family of selfcontained fixed linear voltage regulator integrated circuits. The 78xx family is commonly used in electronic circuits requiring a regulated power supply due to their ease-of-use and low cost.

\subsection{Motor}

The motor is used to convert the electrical input obtained from the IC into useful rotary motion. This rotary motion can be utilised in driving the various components of the machine like the starter ring, power screw and lead screw. The motors used to drive the starter ring are interface to in by means of a starter ring pinion

\subsection{Relay}

Simple electromagnetic Relay consists of a coil of wire wrapped around a soft iron core, an iron yoke which provides a low reluctance path for magnetic flux, a movable iron armature, and one or more sets of contacts

\section{PROGRAMMING}

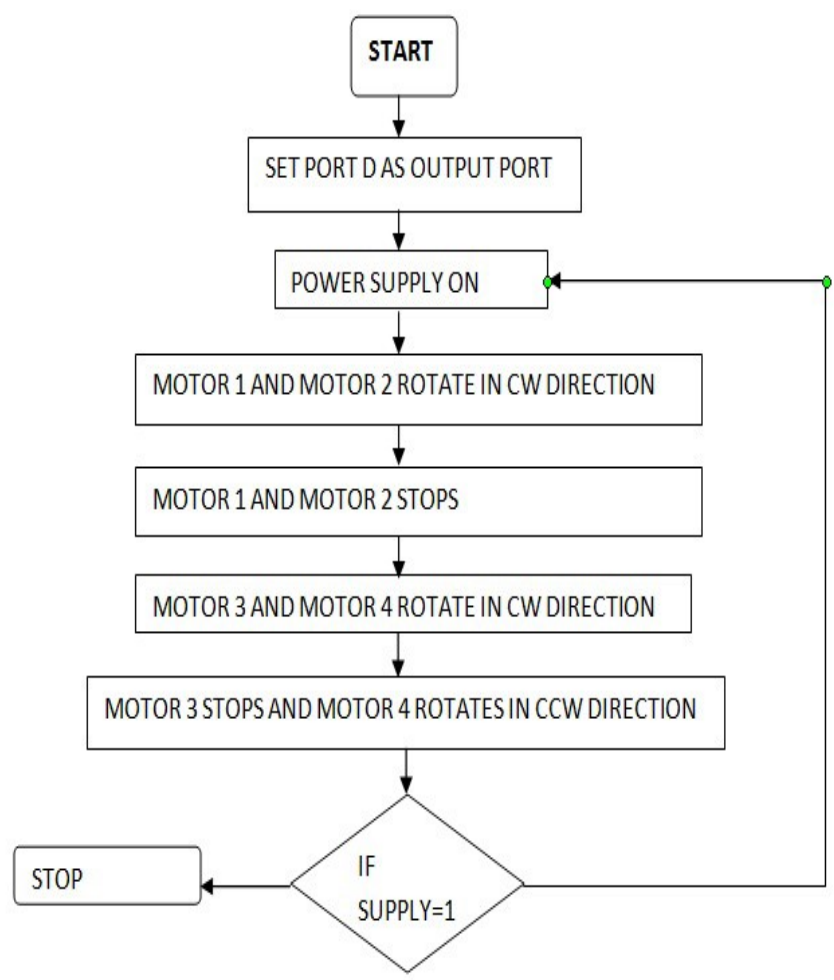

Fig 11. Flowchart of the programme

The main reason For selecting the Atmega8 ic was that it could be easily programmed. The programme was first written in $\mathrm{C}$ language. This programme was then compiled in a compiler to de-bugg the programme. Next, it was converted into a hexadecimal code. Since the Atmmega IC's can only read instructions written in exadecimal format, this was a important step. The out put programme was then burned into the cycle using a suitable burner.

\section{CONCLUSION}

The prototype the special purpose drilling machine to drill holes on the hull of the ship was successfully designed and fabricated and the following objectives were met:

1) A rotary indexing motion to drill holes located in a circular fashion was successfully implemented

2) A linear motion of the bridge was achieved and it increased the range of the machine.

3) A linear vertical feed motion was achieved to drill the holes on the work-piece.

4) The above mentioned motion was automated and flexibility of the machine was improved.

\section{REFERENCES}

[1]. Sharad Kumar Shukla and Akhilesh Lodwa "Experimental analysis of vibration on radial drilling machine using piezoelectric sensor", Bookman International Journal of Mechanical and Civil Engineering, Vol. 2 No. 1 Jan-Feb-Mar 2013

[2]. Akshay R Mahendraker "Automation of Drilling Process Using Electro Pneumatics System" International Journal of Science and Research (IJSR) 2012

[3]. Prof. P.R. Sawant, Mr. R. A.Barawade "Design And Development Of Spm-A Case Study In Multi Drilling And Tapping Machine" International Journal of Advanced Engineering Research and Studies, 2012

[4]. Kaushar H. Barad, Muksh A. Balsara , Giriraj J. Patel, and Saurin M. Sheth" Automation Of Conventional Radial Drilling Machine" National conference on "Innovations in Mechatronics Engineering (IME-09)" 13-14 March, 2009 